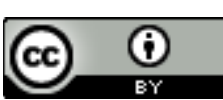

\title{
A CRIANÇA QUEER NO CINEMA E AS SUBVERSÕES DAS NORMAS DE GÊNERO E SEXUALIDADE NA ESCOLA
}

Jamil Cabral Sierra ${ }^{1}$

Maria Rita de Assis César ${ }^{2}$

\begin{abstract}
Resumo
Esse trabalho pretende discutir, a partir de dois filmes de temática queer, Tomboy e Ma vie en rose, como certas experiências com o corpo, o gênero e a sexualidade podem subverter a norma heterossexual e, com isso, ressignificar o próprio espaço da escola tão marcadamente preconceituoso e excludente. Para isso, o texto compõe-se de dois momentos: no primeiro deles, fazemos uma breve análise de como temos concebido a teorização queer, bem como de que maneira temos percebido suas potencialidades tanto teóricas como políticas no deslocamento da objetificação identitária dos corpos e dos gêneros; no segundo momento, tomamos a experiência cinematográfica para pensar como seria possível a constituição de vivências-afetivo-corporais capazes de deslocar o regime heteronormativo que institui os lugares do masculino e do feminino, bem como estabelecer os reflexos disso no campo escolar/educacional.
\end{abstract}

Palavras-chave: Cinema Queer; Gênero; Tomboy; Ma Vie En Rose

\section{SOBRE UMA IDEIA DE VIDA QUEER}

Mesmo que incialmente a expressão queer tenha ganho, no contexto de seu surgimento, essa referência contestatória, à medida que escancarava as abjeções até então invisibilizadas por um estilo de vida gay branco e masculino, com o tempo foi possível

\footnotetext{
${ }^{1}$ Doutor em Educação. Endereço: Rua Treze de Maio, 220, Ap. 112, Centro, Curitiba, Paraná, Brasil. Endereço eletrônico: jamilcasi@gmail.com

${ }^{2}$ Doutora em Educação. Endereço: Rua Mariano Torres, 275, Ap. 101, Centro, Curitiba, Paraná, Brasil. Endereço eletrônico: mritacesar@yahoo.com.br
} 
perceber que "[...] o término queer se volverá objeto de reapropiación mercantil, de academicismo y estetización. Esta rápida dolcegabanización do queer nos ayudaba a reconocer que no era posible ganar la batalla de la resignificación.” (PRECIADO, 2005, p.111).

Essa afirmação de Beatriz Preciado é muito relevante, uma vez que ela escancara os limites da própria teorização queer, os riscos que se corre em transformar o queer em uma identidade, bem como as estratégias que fagocitam o que de perturbador poderia haver no pensamento queer, transformando-o não mais que em uma celebração espetacularizada/fetichizada. Colado, portanto, a esse precioso argumento preciadiano, é que arriscaremos lançar, aqui, outras possibilidades de mobilização do pensamento queer, fazendo-o se distanciar desse momento atual, em que seu uso tem sido cada vez mais incorporado pela teorização e pelas lutas identitárias, para tentar supor não um mero retorno à sua significação inicial de fazer visíveis as abjeções face a um estilo de vida gay higienizado em sua branquitude e em seu machismo, mas sim para pensar como, no presente, é possível potencializar a força subversiva dessa experiência para provocar os necessários tensionamentos na lógica heteronormativa.

Essa ideia é importante e é, em torno dela, que queremos desenvolver o seguinte argumento: queer, da forma como pensamos, é antes de tudo, ou precisaria ser, uma atitude $e^{3}$, um modo de vida - a outra vida, a vida radicalmente outra. Nesse sentido, não cabe supor a dimensão queer de uma vida constituindo uma categoria, constituindo um sujeito empírico, muito menos, constituindo algo como uma nova identidade no já volumoso alfabeto LGBT ${ }^{4}$. Não se trata, pois, de colocar um "Q" no fim da sigla de modo a supor, na dança das letras 5 , mais uma identidade, uma "identidade queer", que seria, por oposição, algo diferente da identidade gay, ou lésbica, ou trans ${ }^{*}{ }^{6}$ a reivindicar seu lugar ao sol e sua posição diante das políticas públicas para a diversidade sexual, por exemplo. Esse artifício descaracterizaria, ao nosso ver, toda potencialidade, força contestatória e subversão queer, inibindo, por

\footnotetext{
${ }^{3}$ Atitude, aqui, tem a ver com a ideia de "atitude de modernidade", descrita por Foucault (1995) e que foi explicitada anteriormente nesse trabalho.

${ }^{4}$ LGBT refere-se a Lésbicas, Gays, Bissexuais, Travestis e Transexuais.

${ }^{5}$ Ver Fachinni (2005).

${ }^{6}$ Trans $^{*}$, com um asterisco no final, refere-se a todas as formas de identificação de gênero que não correspondem à causalidade compulsória "sexo cromossômico-gênero", dentre elas, transexualidade, travestilidade, transgênero, cross-dresser, dentre outras. Esse termo tem sido usado por parte do movimento trans* como um termo guarda-chuva para escapar das denominações classificatórias que sempre poderiam incorrer na exclusão de determinados grupos. Por mais que o termo guarde, ainda, relação com as políticas identitárias do nosso tempo, o trazemos aqui para evitar pulverizar, ainda mais, os nomes que instauram um corpo e um gênero para as pessoas trans. Mais informações sobre isso, em: http://transfeminismo.com/transumbrella-term/
} 
consequência, a possibilidade de fazer vibrar e explodir uma atitude queer, um modo de vida queerizado, uma vez que "[...] se queer é visto primariamente como a base para uma nova política de identidade, então também ele necessariamente irá excluir e restringir;" (SPARGO, 2006, p.36). Ao ser abrigado na seguridade de uma suposta identidade estável, reconhecível, previsível e familiar, o queer perderia seu caráter político mais importante, isto é, o de fazer estranhar, confundir, desfamiliarizar, por meio do escândalo do seu corpo abjeto e de suas práticas sexuais e afetivo-amorosas não reconhecidas pela heteronormatividade, um modo de vida outro.

É esse, portanto, o ponto central: queerizar a vida, da forma como temos concebido, não é materializar empiricamente um certo modelo a ser seguido; não é, também, dar forma reconhecida a uma experiência que, ao estabilizar-se em uma identidade, passaria a compor o novo elemento da tabela, passível, inclusive, de descrição, escrutinação e decifração; não é, ainda, reivindicar a tradução estável e segura de um novo sujeito de direito que, ao sair de seu esgoto, emergiria limpo e inofensivo para disputar, como categoria unificada, ao lado de gays, lésbicas e trans*, seu reconhecimento e sua fatia do bolo. ${ }^{7}$ Nada poderia ser mais desqueerizador que isso. Queerizar a vida precisaria significar uma coisa outra. Precisaria significar uma atitude obscena, estranha, uma atitude inconformada, não-conformada, desenformada, disforme em que, ao queerizar-se, essa vida fosse capaz de ensaiar outros modos de viver, modos de viver contra-sexuais, como diz Preciado, em que o desejo e suas categorias (seja homem ou mulher, seja cis $^{8}$ ou trans*, seja homossexual ou heterossexual) fossem redimensionados em termos de corpos e práticas.

La contra-sexualidad no es la creación de una nueva naturaleza, sino más bien el fín de la Naturaleza como orden que legitima la sujeción de unos cuerpos a otros. La contra-sexualidad es. En primer lugar: una análisis crítico de la diferencia de género

\footnotetext{
${ }^{7}$ Queremos assinalar que, apesar da afirmação acima, não desconsideramos a relevância e a importância das lutas identitárias como forma de reivindicação de direitos específicos aos sujeitos LGBT. Ao contrário, sabemos que no âmbito das lutas por direitos civis e jurídicos esse caminho tem se mostrado capaz de promover avanços significativos. De todo modo, pensamos também ser importante ensaiar uma crítica que, ao levar em consideração tais avanços, seja capaz de propor novas alternativas de contraconduta ética e política.

${ }^{8}$ O prefixo "cis", que pode ser entendido como "mesmo lado", tem sido usado para referir-se às pessoas que vivem em conformidade com a designação que lhes foi imposta a partir do esquema sexo cromossômico-gênero. A expressão, que tem sua origem um pouco incerta, foi incorporada às políticas e teorias trans* como forma de deslocar a centralidade imposta por uma cultura que, ao nomear determinados corpos como trans*, mantinha naturalizada as demais identidades de gênero que alinham-se ao sistema referência sexo/gênero e à heteronormatividade, dando a tais identidades, inclusive, determinados privilégios. Mesmo ainda preservando, de algum modo, uma nomeação que, no limite, acaba impondo uma identidade, pensamos que o uso do prefixo "cis" e suas formas derivadas "cisgênero" e "cissexuais" é importante para mostrar o caráter não natural e arbitrário da suposta correspondência entre sexo cromossômico e identidade de gênero. Sobre esse tema, ver: SIMAKAWA (Viviane V.) (2012). Mais informações em: http://transfeminismo.com/o-que-e-cissexismo/
} 
y de sexo, producto del contrato social heterocentrado, cuyas performatividades normativas han sido inscritas en los cuerpos como verdades biológicas [...]. En segundo lugar: la contra-sexualidad apunta a sustituir este contrato social que denominamos Naturaleza por un contrato contra-sexual. En el marco do contrato contra-sexual, los cuerpos se reconocen a sí mismos no como hombres o mujeres, sino como cuerpos parlantes y reconocen a los otros como cuerpos parlantes. Se reconocen a sí mismos la posibilidad de acceder a todas las prácticas significantes, así como a todas las posiciones de enunciación, en tanto sujetos, que la historia ha determinado como masculinas, femeninas o perversas. (PRECIADO, 2002, p. 18).

Destituir, portanto, do campo da sexualidade normativa uma noção de desejo que seria a materialização da verdade do sujeito, bem como abandonar a ideia de que seria preciso reintroduzir a homossexualidade no caminho da normalidade das convenções sociais para, assim, garantir seu ingresso no campo dos direitos e sua viabilidade-moral-econômica (SIERRA, 2013) no campo do trabalho e do consumo, talvez permitiria uma inversão de posição fundamental: deixar de pensar em termos de uma inserção da homossexualidade num universo sexual e de gênero hegemonicamente já estabelecido para arriscar sonhar com a possibilidade de constituição de vivências-afetivo-corporais ${ }^{9}$ que fossem, radicalmente, outras. Essas vivências a que nos referimos talvez pudessem, a partir justamente de como se vive corpos e práticas sexuais específicos, isto é, justamente por meio do sexo, desviar-se da sexualidade normativa para criar outras relações entre as pessoas, imaginar outros escambos entre corpos, desenvolver outras práticas sexuais. Essas vivências poderiam, ainda, serem capazes de inventar relações que não fossem meramente o símbolo de um escolha feita por um determinado grupo com identificações afins, mas sim que produzissem realmente formas diferentes de interação, completamente despretensiosas no que se refere à suplantação de outras formas interacionais já existentes e que, tampouco, quisessem nelas se transformar. Formas interacionais imprevisíveis, absolutamente radicais em sua despretensão em se tornarem viáveis e modelares, ao contrário, que fossem não mais que um exercício de um grupo com o objetivo de desvincular o sexo da sexualidade para, com isso, ensaiar relações em que o prazer fosse, unicamente, o catalizador dessas novas relações. Essa é a virada crucial: não pensar o desejo como algo a priori, anterior à prática, mas como algo que pode ou não surgir, para algumas pessoas, com a invenção de outras práticas sexuais, isto é, de outros prazeres. Como diz Foucault: "Creio que uma abordagem interessante seria fazer com

\footnotetext{
${ }^{9}$ Vivências-afetivo-corporais está sendo usado aqui como alternativa a um determinado conjunto de termos que, vinculados à noção de identidade, não seriam eficientes em traduzir o efeito linguístico pretendido: caracterizar o que seriam essas formas culturais capazes de ensejar modos de vida diferentes a partir do uso que se faz do corpo e de suas práticas. Como tais usos e práticas não se associam especificamente a uma identidade singular (ou gay, ou lésbica, ou bi, ou trans*), pensamos que vivências-afetivo-corporais pode ser mais abrangente no objetivo de dizer que tais usos e práticas, antes de serem propriedade de uma categoria específica, são atitudes possíveis de transversalizar e, portanto, esfumaçar as fronteiras entre as identidades.
} 
que o prazer da relação sexual escape do campo normativo da sexualidade e de suas categorias, e por isso mesmo fazer do prazer o ponto de cristalização de uma nova cultura". (2010b, p. 123).

Assim, quem sabe, fosse possível pensar em outras vivências-afetivo-corporais, em que as relações entre as pessoas, seja por meio da amizade, como diz Foucault (2010a), seja por meio de outros jogos interacionais, pudessem constituir modos de vida diferentes, deflagradores de uma atitude transformadora diante dos horrores que nosso tempo tem assistido e que promovem, com violência e dor, o extermínio de culturas subalternas. Essas vivências-afetivo-corporais poderiam, ainda, ao tensionar a cultura sexual hegemônica, fraturá-la a tal ponto de provocar nela novas referências sem, contudo, ter a arrogante pretensão de absorvê-la ou eliminá-la.

Nesse sentido, tomar o queer nessa acepção significaria pensá-lo a partir da constituição de outras maneiras de viver os corpos, os prazeres, os afetos e os amores. Se em seu processo de constituição o queer foi assumido como adjetivo confrontativo frente à respeitabilidade gay e lésbica; se em seu percurso de desenvolvimento essa adjetivação foi transformada em substantivo, a marcar fronteiras do que pode e do que não pode ser queer, o que propomos, agora, é seu redimensionamento para verbo. Como verbo, queer (queerizarselqueering) está mais para a prática que para a teoria ou qualidade: queer como aquilo que se pratica - uma ação entre corpos, uma atitude diante da vida. Concebido, assim, queer não se constituiria em uma identidade, espécie de corporação empírica aglutinadora de sujeitos com características afins. Ao contrário, queer atravessaria, feito navalha a cortar o que vier pela frente, diferentes manifestações de vida, sejam essas vidas heterossexuais ou homossexuais, trans* ou cis, desde que haja nelas um trabalho ético, estético e político sobre si mesmas, a promover a necessária subversão da heteronormatividade, bem como um deslocamento impiedoso dos regimes políticos de inclusão neoliberais que, associados, aprisionam corpos e práticas na lógica objetivadora e excludente das identidades.

Para isso seria preciso pensar que

[...] as relações que devemos estabelecer conosco mesmos não são relações de identidade, elas devem ser antes relações de diferenciação, de criação, de inovação. É muito chato ser sempre o mesmo. Nós não devemos excluir a identidade se é pelo viés da identidade que as pessoas encontram seu prazer, mas não devemos considerar essa identidade como uma regra ética universal. (FOUCAULT, 2004a, p.262). 
É portanto com base nessa compreensão que temos de vida queer e de usa potência estético-política, que passamos ao segundo momento desse texto.

\section{O QUE O CINEMA QUEER PODE ENSINAR À ESCOLA?}

A cena se abre com uma imagem da nuca de uma criança que está quase solta no ar, com os braços levantados, leve, como se pudesse voar. A nuca à mostra revela um corte de cabelo muito curto e o espelho refletindo um torso magro teima em mostrar ser um corpo infantil.

Trata-se do filme Tomboy, de 2011, dirigido pela jovem diretora Céline Scianma. ${ }^{10}$ Como o filme é francês, a diretora pode ter imaginado que o público não saberia o significado da palavra na Língua Inglesa (tomboy) escolhida para o título. Se a palavra não for conhecida do público o mistério sobre aquela criança levaria alguns minutos a ser desvendado. Por outro lado, se já se sabe o significado de tomboy, expressão inglesa para denominar 'meninamoleque', 'menina-travessa', 'menina-macho', ou ainda 'lésbica', o suspense se mantém de outra forma, anunciando o momento da descoberta: a insustentável leveza daquele corpo de criança que teima em manter uma inapreensível identidade de gênero. A insustentabilidade daquele corpo instaura, em que assiste ao filme, uma certa angústia em relação ao enredo. Quando, onde e como aquele corpo terá peso? Quando, onde e como será 'descoberto'? Quando a inteligibilidade daquele corpo será acionada a partir do sistema corpo-sexo-gênero? A sustentabilidade dos corpos só poderá se dar na medida em que estes são compreensíveis dentro de uma norma estabelecida no interior do sistema corpo-sexo-gênero.

Aquela criança-tomboy acaba de se mudar com sua família para uma nova cidade, uma nova casa e a mãe grávida de um menino também representa uma nova mudança na família. A mãe é carinhosa e compreensiva, diz que pintou o quarto de azul como ela/ele queria. O pai também é amoroso e a/o trata com uma cumplicidade que pode ser entendida como uma cumplicidade de gênero, oferecendo um gole de cerveja ou ensinando a dirigir. A família feliz está desenhada: um pai companheiro, uma mãe grávida e uma irmãzinha cheia de afeto. Ao descer as escadas do prédio para fazer o reconhecimento do novo lugar e da nova turma, uma garota vem a seu encontro. "Me chamo Lisa, e você?" A resposta vem quase como um sussurro: "Michaël". Ao atribui-se o nome de Michaël, tanto a criança como o filme iniciam um processo de invenção de gênero e de uma identidade masculina.

\footnotetext{
${ }^{10}$ Tomboy. (França, 2011).
} 
Em outra cena as crianças estão na banheira brincando com sabão nos cabelos. Ao ouvir o chamado da mãe para virem à mesa do jantar, Jeanne, a irmã mais nova, sai da banheira e, em seguida, se constrói a cena revelação. Aquele corpinho magro - que se o público estivesse completamente ignorante em relação à temática do filme poderia ser tomado até então como um garoto - se levanta nu 'mostrando' ser uma garota. A cena é rápida e produz desconforto, mesmo em quem já sabe do que se trata o filme. Ainda há uma última esperança de se encontrar Michaël naquele corpo. Mas não. Michaël é uma garota. A câmara ligeira e silenciosa de Scianma nos devolve como uma bofetada a ideia de que a inteligibilidade do gênero se dá um corpo sexuado. Uma garota? Mas Michaël é uma garota? Sim, é Laure quem vem jantar com a família.

Céline Scianma na sequencia inicial do filme nos levaria a crer que se trata de uma garoto: o cabelo curto, os gestos, as roupas, as brincadeiras com o pai e o cuidado com a irmã. Há sim uma razão narrativa que sustenta o enredo a partir da dúvida, da construção e da descoberta que se desenrola em torno da identidade de Laure/Michaël. O corpo da jovem atriz Zoé Héran (Laure/Michaël) é tomado pela lente de Scianma como um possível garoto e tudo nos leva a crer sobre essa possibilidade. O olhar da diretora identifica e produz identificação. Para quem assiste trata-se de um garoto e há identificação com esse garoto. Essa identificação nos acompanha até o final da narrativa, deixando Michaël, aos olhos de quem vê o filme, mais convincente do que Laure.

Nesse ponto nos encontramos com as indagações de Judith Butler sobre a ideia de corpo. Para ela, pensado no interior do sistema corpo-sexo-gênero, o corpo será sempre sexuado e generificado. Para Butler, o gênero se coloca sempre anterior ao sexo e ao corpo. (BUTLER, 1990; 1993). Com esta primeira revelação, trata-se de uma garota (Laure) e não de um garoto (Michaël). Os próximos passos serão o desenrolar do enredo em torno desse gender trouble/problema-desacordo de gênero.

Outro filme que também tratou desse gender trouble $e^{11}$ na infância fez sua aparição nos cinemas europeus e norte-americanos na segunda metade da década de 1990. Ma vie en rose/Minha vida em cor-de-rosa ${ }^{12}$ tem algumas semelhanças com Tomboy: uma família em mudança de cidade e um garoto de sete anos que afirma ser menina. Na cena inicial do filme a família está fazendo uma festa de apresentação para a vizinhança e, nesse momento, as personagens são introduzidas. Anne/mãe, a mais bela; o filho mais velho, o rei da matemática;

\footnotetext{
${ }^{11}$ Gender Trouble é uma referência explícita ao título da obra de Judith Butler (1990).

${ }^{12}$ Ma vie en rose (França; Bélgica e Reino Unido, 1997). Direção: Alaine Berliner.
} 
o filho do meio, o rei da traquinagem e, ao chamar a filha mais velha, todos aplaudem uma linda princesa. Trate-se, porém, de Ludovic, que o pai sem jeito chama de o rei do disfarce. A mãe corre em direção a Ludovic para dizer que aos sete anos ele não pode mais fazer aquilo. A narrativa de Ma vie en rose mescla os olhares dos adultos, de Ludovic e também de uma boneca que participa da história. A boneca é tanto seu modelo de feminilidade, como o lugar de refúgio do seu gender trouble. Entretanto, a narrativa está centrada na forma como os adultos e as instituições vão lidar com o desejo de Ludovic de ser uma menina. A história se desenrola a partir da violência impetrada contra aquele menino que quer ser uma menina e deseja se casar com o filho do vizinho que, por sua vez, é o filho do patrão do seu pai. Após ouvir uma explicação da irmã sobre cromossomos, Ludovic está seguro de que Deus é um malandro, pois, em suas palavras, ele não distribuiu corretamente seu par de cromossomos XX, deixando cair um Y no lugar do X. Para Ludovic, esse Deus malandrinho irá enviar seu $\mathrm{X}$ e tudo estará resolvido. Essa explicação o/a garoto/a dá várias vezes durante a narrativa. “Je suis un garçon-fille" (eu sou um menino-menina).

Diferentemente de Tomboy, em que Laure/Michaël cria formas para enganar os garotos do bairro e a menina Lisa, Ludovic tem que convencer, sem sucesso, os adultos e outras crianças de que, na verdade, é 'quase' uma menina. Laure/Michaël joga futebol sem camisa e cospe no chão. Em uma sequencia genial, convidada/o para um banho no lago tem que improvisar uma sunga com seu maiô feminino e, além disso, esculpe cuidadosamente um pênis de massinha de modelar para dar volume em um púbis que teima em carregar outras marcas. Após o uso, o pênis de massinha é guardado cuidadosamente em uma caixinha junto a outras partes do corpo de Laure/ Michaël: seus dentes de leite que caíram. A simulação funciona perfeitamente, ela/ele é um garoto comme il fault (como se deve ser). Ludovic não quer enganar; ao contrário, ele/ela quer ser autêntico/a. Tal autenticidade para ele/ela significa brincar com a boneca, usar saia, maquiagem e se casar no futuro com o filho do vizinho que, em princípio, também aceita a explicação.

Laure/Michaël precisa enganar. Quando Lisa vai a sua casa perguntando por Michaël, a irmãzinha entende a situação e entra no jogo porque assim também irá fingir que tem um irmão mais velho que a protegerá. Em Tomboy, os adultos estão quase ausentes, a mãe grávida precisa ficar muito tempo em repouso e o pai trabalha em um novo emprego. As crianças aproveitam o final de verão, o calor, a atmosfera do final das férias para que em pouco tempo retornem à escola. A escola é a maior preocupação de Laure/Michaël. Lisa já anunciou que desconhece qualquer Michaël em sua classe. 
Depois de uma briga, a mãe do garoto ferido vem tirar satisfação com Michaël. Nesse momento, a mãe de Laure percebe a 'farsa' e diz que ali não há garotos. Esse é o ponto culminante de tensão narrativa, quando a mãe obriga Laure/Michaël a vestir um vestido e ir à casa do garoto pedir desculpas e mostrar que é, na verdade, uma menina. A mãe diz: "Escuta, não estou fazendo isso para lhe fazer um mal ou dar uma lição. Sou obrigada, entende? Não me incomodo que você brinque de ser um menino. E tampouco me aborrece, mas isso não pode continuar. Se tem alguma outra ideia me fale, porque eu não vejo outra saída. Você tem uma solução?” A fala da mãe é repleta de ambiguidades, diferentemente da fala da mãe de Ludovic que explica ao filho que ele é "viado" e que "viado" são os garotos como ele que gostam de outros garotos.

Para a mãe de Laure/Michaël fica ainda a 'falta' de uma solução. Não há explicações moralizantes, tentativas de "cura" etc. Há uma enorme lacuna, uma vazio, um não saber o que e como fazer. Ela diz: “... eu sou obrigada, entende?” Obrigada por quem? Quem a obriga a uma atitude violenta e vexatória? É possível que nem ela mesma saiba. Ela pede para a filha uma solução. Talvez ela quisesse fazer de outro jeito. Ela afirma que não se incomoda com aquilo, mas com o quê exatamente então? Certamente, isso está marcado por uma vida imersa em uma experiência contemporânea, na qual ela sabe que lésbicas e gays estão completamente inseridos no mundo e que apesar do preconceito de sofrem são felizes. Entretanto, naquela situação, a infância, a escola, a vizinhança, as outras crianças, isso está para além das suas possibilidades de pensar em uma solução não violenta, uma vez que a situação está para além da possibilidade de acolhimento. Por quê?

Em um texto recente publicado pela filósofa, estudiosa feminista e ativista queer Beatriz Preciado, em resposta às enormes manifestações que os grupos da direita-católica francesa realizaram em reação à tramitação da lei pelo casamento igualitário, Preciado escreveu sobre a criança queer, ou como o título do texto expressou, "Quem defende/protege a criança queer?" (PRECIADO, 2013). No texto, Preciado afirma que aquela criança que as manifestações desejam proteger, no caso da parentalidade de casais homossexuais, porque a lei francesa aprovada recentemente estende para todos os casais (heterossexuais e homossexuais) o direito a adoção e a reprodução assistida, não passa de um fantasma que garanta a permanência da norma heterossexual. Para Preciado (2013): 
A criança a ser protegida, de Frigide Barjot $^{13}$, é o resultado de um dispositivo pedagógico terrível, o lugar onde se projetam todos os fantasmas, a justificativa que permite que o adulto naturalize a norma. A biopolítica é vivípara e pedófila. A reprodução nacional depende disso. A criança é um artefato biopolítico que garante a normalização do adulto. A polícia de gênero vigia o berço dos seres que estão por nascer, para transformá-los em crianças heterossexuais. A norma ronda os corpos meigos. Se você não é heterossexual, é a morte o que te espera. A polícia de gênero exige qualidades diferentes do menino e da menina. Dá forma aos corpos com o objetivo de desenhar órgãos sexuais complementares. Prepara a reprodução da norma, da escola até o Congresso, transformando isso numa questão industrial. ${ }^{14}$

A autora faz no texto um relato da sua infância e das violências sofridas nas mãos da escola, da psiquiatria e da família por também ter sido uma criança queer. Nesse contexto, ela relata um episódio que deu início a uma sucessão de violências.

Eu tinha sete anos. Desenhei a mim casada com minha melhor amiga, Marta, três crianças e vários cachorros e gatas. Eu tinha imaginado uma utopia sexual, na qual existia casamento para todos, adoção, PMA... Alguns dias depois a escola enviou uma carta à minha casa, aconselhando os meus pais a me levarem a um psiquiatra, afim de consertar o mais rápido possível o problema de identificação sexual. Depois dessa visita, vieram várias represálias. Na escola foi espalhado o rumor de que eu era lésbica. (PRECIADO, 2013).

Preciado afirma que a heteronormatividade sequestrou a sua família, e que não teve pai e mãe que pudessem protegê-la e amá-la, mas sim soldados de uma norma sexual obrigatória, pois abriram mão da maternidade e da paternidade para se fazerem guardas da heteronormatividade.

Os manifestantes de 13 de janeiro de 2013 não defendem o direito da criança. Eles defendem o poder de educar os filhos dentro da norma sexual e de gênero, com princípios heterossexuais. Eles desfilam para conservar o direito de discriminar, castigas e corrigir qualquer forma de dissidência ou desvio, mas também para lembrar aos pais dos filhos não-heterossexuais que o seu dever é ter vergonha deles, rejeitá-los e corrigi-los. Nós defendemos o direito das crianças a não serem educadas exclusivamente como força de trabalho e de reprodução. Defendemos o direito das crianças e adolescentes a não serem futuros produtores de esperma e futuros úteros. Defendemos o direito das crianças a dos adolescentes a serem subjetividades políticas que não se reduzem a identidade de gênero, sexo ou raça. (PRECIADO, 2013).

Laure/Michaël e Ludovic são crianças queer, crianças não heterossexuais. Cada uma delas, assim como Preciado em seu desenho, criou para si uma utopia sexual. Laure, agora Michaël, modelou um pênis e pode nadar com os garotos e beijar as garotas. Ludovic, na sua

\footnotetext{
${ }^{13}$ Frigide Barjot é a principal representante das manifestações contrárias ao casamento igualitário na França. Ela liderou um movimento de proteção a infância em contraposição ao casamento igualitário para todos.

${ }^{14}$ A tradução dessa e de outras citações extraídas desse texto foram feitas por nós mesmos.
} 
fantasia de boneca, pode se casar com Jerôme vestido/a de princesa. Entretanto, a família e a escola insistem em impor as regras da heteronormatividade. Ludovic foi expulso da escola em razão de "comportamento extravagante" e é a escola que preocupa Laure/Michaël nas próximas semanas, com o início das aulas. Como diz a personagem Lisa: "não há nenhum Michaël na minha classe".

Por que nós, que assistimos a esses filmes, criamos uma identificação tão grande com Laure/Michaël e Ludovic nas telas de projeção, torcendo para que uma suposta 'verdade' do sexo e do gênero não seja revelada, enquanto as escolas, tanto no filme como na vida real, permanecem insistindo em não criar nenhuma identificação, nem mesmo compaixão, pelas crianças e adolescentes não heterossexuais ou não normativos? As escolas, salvo raras exceções, permanecem como lugares da violência, tão bem definidos por Preciado. As escolas permanecem como quarteis guardiões das normas de gênero, do corpo e da sexualidade, idênticas àquelas presentes nas bandeiras e estandartes das manifestações parisienses da extrema-direita-católica.

Embora haja um conjunto de leis e decretos que garante o aceso nas escolas de crianças e adolescentes queer, as práticas cotidianas escolares teimam em sustentar que a escola permaneça como um lugar insuportável para essas crianças e adolescentes. No Brasil, há inúmeras iniciativas que lutam por uma pedagogia não heteronormativa. No contexto do Ministério da Educação há programas de formação continuada para professores/as, nas universidades há cursos, projetos de pesquisa e extensão; são produzidas teses e dissertações, além de material didático e paradidático para as escolas. As secretarias estaduais de educação criam departamentos específicos para tratar a questão, além de uma legislação que possa reger o ingresso e a permanência dessas crianças e jovens nas escolas, mas parece que nada disso é suficiente.

A utilização do nome social de travestis e transexuais é uma questão importante trazida pelos próprios coletivos sociais LGBT. Embora já reconhecido em algumas instituições e motivo de projetos de leis e decretos, o nome social permanece como um tabu e, em relação a crianças e adolescentes, a questão se torna insuportável. As autoridades institucionais, que zelam pelo funcionamento da norma, não permitem a sua utilização. $O$ nome no interior da instituição escolar é fundamental, pois este é objeto constante de escrutínio, tanto por parte dos/as professores/as e staff institucional, como também por parte dos/as alunos/as. Nomes dúbios com terminações indefinidas são motivos de humilhação e discriminação, que sempre reafirmam a norma heterossexual. 
Uma discussão bastante contemporânea diz respeito à questão do acolhimento de crianças e adolescentes trans* nas escolas. Mesmo com a implementação de leis que garantem o uso do nome social de pessoas trans* na instituição escolar, hoje o debate se dá em torno da eliminação a maioridade para o atendimento da lei. Desse modo, a futura implementação de novas leis e resoluções que abrem a possibilidade e instauram a obrigatoriedade da inclusão dos nomes sociais nas listas de chamadas, com a garantia do seu emprego no interior da instituição escolar, irá criar a possibilidade de acolhimento também da experiência trans* de crianças e jovens no interior da escola. Dois caminhos serão possíveis: um primeiro e mais fácil, será a aceitação por meio da problemática 'pedagogia da tolerância', na qual nunca se questionam os sistemas normativos; um segundo, mais difícil, será aquele que irá produzir interrogações sobre a heteronormatividade no interior da instituição escolar. (CESAR, 2010).

Nesse sentido, conforme dissemos no início desse texto, não cabe só queerizar a vida, mas também a escola. A Teoria Queer, partindo de indagações realizadas tanto por Michel Foucault como por Judith Butler e Beatriz Preciado, representa um acervo importante de novas "perguntas-respostas", pois não é prescritiva e questiona principalmente as condições de possibilidade de um conhecimento (SPARGO, 2006). Ao tratar da Teoria Queer, Guacira Lopes Louro (2004, p.65) diz que: “[...] há limites para o conhecimento: nessa perspectiva, parece importante indagar o que ou quanto um dado grupo suporta conhecer".

Os limites do discurso do sexo e do gênero são marcados por sua concepção naturalizada, a-histórica e, consequentemente, imutável. E mesmo que tomemos o gênero como construção social, as teorias construcionistas nunca conseguiram se desvincular de uma matriz naturalista e essencializadora. (BUTLER, 1990). Nessa perspectiva, o sexo e também o gênero estão confinados a uma percepção naturalizada que delimita fronteiras e produz sujeitos dicotômicos: masculino/feminino, heterossexual/homossexual e normal/anormal. Contra isso, uma pedagogia queer e suas indagações poderão apresentar um corpus teórico fundamental sobre educação, gênero e sexualidade. Desse modo, Laure/Michaël, Ludovic, entre tantos/as outro/as que existem e povoam nossas escolas, poderiam ter o direito a uma educação livre da violência que é exercida cotidianamente contra aqueles/as que estão fora das normas de gênero e desafiam a heteronormatividade.

\title{
THE QUEER CHILD IN THE MOVIES AND THE SUBVERSION OF GENDER NORMS AND OF SEXUALITY IN THE SCHOOL
}

\author{
Abstract


Discussing two movies inspired by queer thematics, Tomboy and Ma vie en rose, this article intends to analyze how certain experiences with the body, gender and sexuality may subvert the heterosexual norm and thus re-signify the schools' social space, overtly pre-judgmental and excluding. The text is composed by two related moments: in the first one, we propose a short discussion centered on our understanding of queer theory and its political and theoretical potentialities. We think that queer theory is fundamental in questioning and displacing the identitarian objectification of bodies and genders. In the second moment, we discuss those movies in order to think the possibility of bodily-and-affective experiences which displace the heteronormative regime that institutes definite places for the masculine and the feminine. We also intend to point out what are the consequences of those previous analysis concerning the school and the educational field.

Keywords: Queer Movies; Gender; Tomboy; Ma Vie En Rose

\section{NIÑO QUEER EN EL CINE Y SUBVENCIONES DE LAS REGLAS DEL GÉNERO Y SEXUALIDAD EN LA ESCUELA}

\section{Resumen}

Este trabajo intenta discutir, a partir de películas de temática queer, Tomboy y Ma vie en Rose, como ciertas experiencias con el cuerpo, el género y la sexualidad pueden subvertir la norma heterosexual y, de esa manera, dar otro significado al propio espacio de la escuela, tan marcadamente prejuicioso y excluyente. Para eso, el texto se compone de dos momentos: en un primer momento, hacemos un breve análisis sobre cómo concebimos la teoría queer y sobre cómo hemos comprendido sus potencialidades teóricas y políticas en cuanto al desplazamiento de la objectificación identitária de cuerpos y géneros. En un segundo momento tomamos la experiencia cinematográfica para pensar como sería posible la constitución de vivencias-afectivo-corporales capaces de desplazar el régimen heteronormativo que instituye los lugares del masculino y del femenino, así como para establecer los reflejos de tal desplazamiento en el campo escolar/educativo.

Palabras clave: Películas Queer, Género, Tomboy, M Vie En Rose

\section{REFERÊNCIAS}


BUTLER, Judith. Gender Trouble. Feminism and the subversion of identity. New. York: Routledge, 1990.

Bodies that matter. On the discursive limits of "sex". New York: Routledge, 1993.

CÉSAR, Maria Rita de Assis. As novas práticas de governo na escola: corpo e sexualidade entre o centro e a margem. In: CASTELO BRANCO, G.; VEIGA-NETO, A. (Orgs.) Foucault filosofia e política. Belo Horizonte: Autêntica, 2010.

FACHINNI, Regina. Sopa de Letrinhas: movimento homossexual e produção de identidades coletivas nos anos 90. Rio de Janeiro. Garamond, 2005.

FOUCAULT, Michel. Da amizade como modo de vida. In: . Ditos \& Escritos. Vol. VI. Repensar a Política. Rio de Janeiro: Forense Universitária, 2010a.

Michel Foucault, uma entrevista: sexo, poder e a política da identidade. Revista Verve, 5, 2004. p. 260-277.

O Triunfo social do prazer sexual: uma conversação com Michel Foucault. In: FOUCUALT, Michel. Ditos \& Escritos, Vol. V. Ética, Sexualidade, Política. 2 ed. Rio de Janeiro: Forense Universitária, 2010b.

LOURO, Guacira Lopes. Um corpo estranho: ensaios sobre sexualidade e teoria queer. Belo Horizonte: Autêntica, 2004.

PRECIADO, Beatriz. Devenir bollo-lobo o como hacerse un cuerpo queer a partir de $E l$ pensamiento heterosexual. In: Córdoba, David; Sáez, Javier; Vidarte, Paco. Teoría Queer. Políticas bolleras, maricas, trans, mestizas. Barcelona: Editorial Egales, 2005.

Prima, 2002.

. Manifesto contra-sexual. Prácticas subversivas de identidad sexual. Madri: Obra

Qui defénd l'enfant queer? Liberation, 2013.

http://www.liberation.fr/societe/2013/01/14/qui-defend-1-enfant-queer_873947

SIERRA, Jamil Cabral. Marcos da vida viável, marcas da vida vivível - O governamento da diversidade sexual e o desafio de uma ética/estética pós-identitária para a teorização políticoeducacional LGBT. Tese de doutorado. Universidade Federal do Paraná. 2013.

SIMAKAWA (Viviane V.), Douglas Takeshi. Pela descolonização das identidades trans. In: Anais do IV Congresso Internacional de Estudos sobre a Diversidade Sexual e de Gênero da ABEH. 2012.

SPARGO, Tamsim. Foucault e a Teoria Queer. Rio de Janeiro: Pazulin; Juiz de Fora: Ed. UFJF, 2006. 